\title{
The Influence and Mechanism of Residual Stress on the Corrosion Behavior of Welded Structures
}

\author{
Linyue Bai ${ }^{a}$, Kebin Jiang ${ }^{a} *$ ¿ Lei Gao ${ }^{a} \mathbb{1}$ \\ ${ }^{a}$ Field Engineering Institute, Army Engineering University of PLA, Nanjing, Jiangsu, China
}

Received: June 26, 2017; Revised: March 04, 2018; Accepted: June 25, 2018

\begin{abstract}
To study the influence of residual stress on the corrosion behavior of welded structures, methods such as residual stress measurement, microstructure observation, and corrosion morphology observation were used. The energy transformation model and corrosion-resistance constant model were utilized to reveal the mechanism of residual stress on the welded structures' corrosion behavior. The results show that the fusion line was the region that is most heavily affected by corrosion and sustains more serious corrosion damage than other areas, resulting in the welded structure becoming a high-incidence area for corrosion cracking and failure. Residual tensile stress could reduce the activation energy and surface atomic density, and therefore decrease the corrosion resistance of the welded structures. The residual compressive stress decreased the activation energy needed by metal atoms to convert into metal ions in welded structures, and simultaneously increased the surface atomic density. The corrosion resistance of the welded structures ultimately increased owing to the combined influence of changes in activation energy and surface atomic density.
\end{abstract}

Keywords: Residual stress, Welded structures, Corrosion, Energy transformation model, Corrosion-resistance constant model.

\section{Introduction}

Due to good connection performance and excellent air tightness, welding fabrication has been extensive applied in the manufacturing of steel structures ${ }^{1-4}$. However, the welding residual stress has great influence on the corrosion resistance of welded structures while the structures serve in a corrosive environment, thus effecting their security and service life ${ }^{5-8}$. Methods such as heat treatment and vibratory stress relief (VSR) are usually used to eliminate the residual stress in welded structures to reduce its effects on the structures ${ }^{9-11}$. However, it is difficult to eliminate the residual stress completely, especially in large-scale steel structures. Therefore, investigating the influence and mechanism of residual stress on the corrosion behavior of welded structures is important for the purpose of improving the performance of welded structures.

The influences on the corrosion resistance of welded structures by residual tensile stress and residual compressive stress are different, which increases the complexity of the investigation on the influence and mechanism of residual stress on the corrosion behavior. Numerous studies have indicated that residual tensile stress can not only increase the susceptibility of welded structures to corrosion cracking and the growth rate of corrosion cracks, but can also decrease their corrosion resistance ${ }^{12-15}$. Compared with studies of residual tensile stress, reports on the influence of residual compressive stress on the welded structures' corrosion behavior are few. Furthermore, the theoretical analyses that

*e-mail:kbjiang1122@sina.com could be used to reveal the influences and mechanisms of both residual tensile stress and residual compressive stress on the corrosion behavior are even fewer.

As a measurement of state transitions between types of matter, energy can establish the relationship between several physical and chemical processes. Therefore, the energy theory could be effective in establishing the relationship between the residual stress and corrosion behavior, and thus clarify the influence of residual stress on the corrosion behavior of welded structures. However, it is not enough to explain the corrosion mechanism of welded structures under the influence of residual tensile stress and residual compressive stress through the energy theory alone. Thus, research on the kinetics relationship of electrode reactions in the corrosion process is simultaneously needed, in order to achieve a method for revealing the influences and mechanisms of residual tensile stress and residual compressive stress on the corrosion behavior.

The corrosion behavior of welded structures immersed in natural seawater was investigated in this paper. Before the corrosion test, residual stress in some of the welded specimens was reduced by VSR, and the residual stress on the surface of welded specimens was measured by a stress magnetometer. To determine the influence and mechanism of residual stress on the corrosion behavior of welded structures, the microstructures and corrosion morphologies of various zones of welded specimens with different residual stress levels were observed. The influence of residual stress on the corrosion behavior of welded structures was achieved through the investigation on the relationships of energy 
transformations during corrosion. The surface atomic density, which represents the number of atoms per unit area on a metal surface, was introduced into the Arrhenius equation ${ }^{16}$, and a corrosion-resistance constant model was constructed to explain the influence mechanisms of residual tensile stress and residual compressive stress on the corrosion behavior of welded structures.

\section{Experiment}

\subsection{Sample preparation}

The material used in the experiment was X65 steel, whose chemical components are listed in Table 1 . The dimensions of welded specimens were $350 \mathrm{~mm} \times 150 \mathrm{~mm} \times 10 \mathrm{~mm}$, and the schematic of the groove is shown in Figure 1. All specimens were processed via root welding by cellulose

electrode. Additionally, semi-automatic self-protection welding with flux-cored wire was utilized in weld beads for filling and covering. Cellulose electrodes were E6010 and flux-cored wire was E71T8-K6. Welding parameters for each layer of weld are shown in Table 2.

After processing, the welded specimens were separated into two groups, numbered A1 and A2. There were three specimens in each group, numbering A1-1, A1-2...A2-2, A2-3. To reduce the residual stress in the specimens of group A2, vibration was imposed by a high speed motor on specimens via the VSR method before the corrosion test. The surface of specimens of both groups were burnished before measurement to meet the requirements of the stress magnetometer.

\subsection{Residual stress measurement}

Table 1. Chemical components of X65 steel

\begin{tabular}{lcccccccccc}
\hline Elements & $\mathrm{C}$ & $\mathrm{Si}$ & $\mathrm{Mn}$ & $\mathrm{P}$ & $\mathrm{S}$ & $\mathrm{V}$ & $\mathrm{Nb}$ & $\mathrm{Ti}$ & $\mathrm{Fe}$ \\
\hline \multirow{2}{*}{ Wt. $\%$} & $\max$ & $\max$ & $\max$ & $\max$ & $\max$ & $\max$ & $\max$ & $\max$ & Bal. \\
& 0.16 & 0.45 & 1.60 & 0.025 & 0.015 & 0.10 & 0.06 & 0.05 & \\
\hline
\end{tabular}

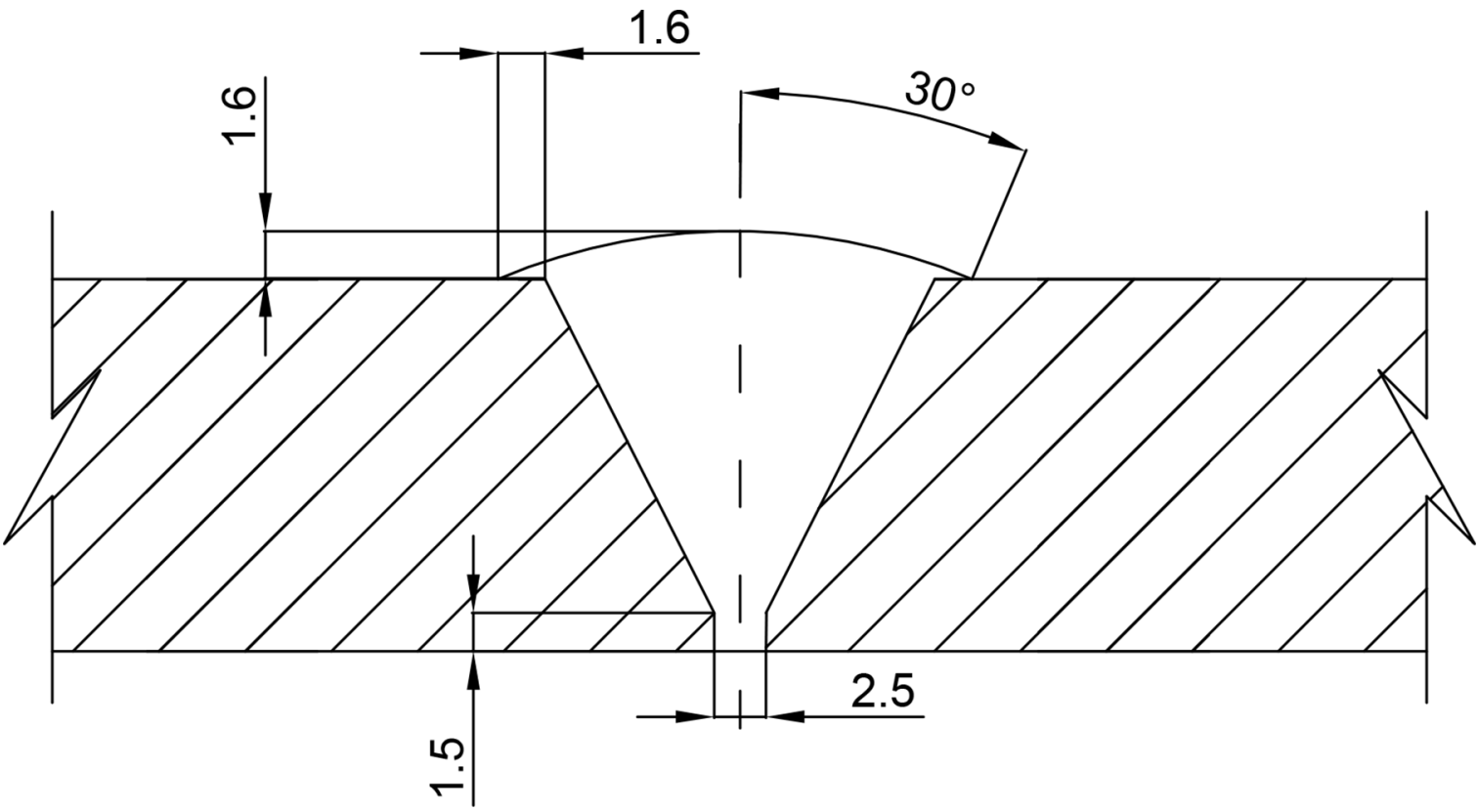

Figure 1. Groove schematic

Table 2. Welding parameters

\begin{tabular}{|c|c|c|c|c|c|}
\hline weld bead & $\begin{array}{c}\text { Grades and } \\
\text { specifications of } \\
\text { welding } \\
\text { consumables }(\mathrm{mm})\end{array}$ & polarity & $\begin{array}{l}\text { welding current } \\
\text { (A) }\end{array}$ & $\begin{array}{l}\text { arc voltage } \\
\text { (V) }\end{array}$ & $\begin{array}{l}\text { welding speed } \\
(\mathrm{cm} / \mathrm{min})\end{array}$ \\
\hline root welding & $\mathrm{E} 6010, \varphi 3.2$ & negative & $60-90$ & $25 \sim 35$ & $6 \sim 13$ \\
\hline hot welding & & & $180-250$ & & $15 \sim 30$ \\
\hline filling & E71T8-K6, $\varphi 2.0$ & positive & $160-240$ & $18 \sim 19$ & $12 \sim 25$ \\
\hline facing & & & $160 \sim 240$ & & $12 \sim 25$ \\
\hline
\end{tabular}


In order to confirm the residual stress relieving effect of the VSR method, a three-dimensional stress magnetometer (JH-80) was used to measure the residual stress on the surface of the specimens of group A2 before and after VSR. The residual stress on the surface of specimens of group A1 was also measured. Limited by the specimen size, only the transversal residual stress on the surface of specimens was measured. In order to improve accuracy of the measurement, the sensitivity coefficient of X65 steel was determined by the three-dimensional stress magnetometer before the residual stress measurement was undertaken. The value of X65 steel's sensitivity coefficient was $0.0153 \mathrm{~mA} / \mathrm{MPa}$, which was calculated from the detection results.

\subsection{Seawater corrosion test}

The corrosion test was conducted in accordance with GB/T 6384-2008 in natural seawater for 60 days, to reduce the interference of the external environment in the energy transformation while corroding. The natural seawater was derived from the East China Sea, whose major chemical components are listed in Table 3 . The welded specimen was connected with a graphite flake through wire to constitute a galvanic cell structure while corroding, in order to increase the corrosion rate of the welded specimen. While the specimens were immersed in the seawater, distances of $2 \mathrm{~m}$ and $0.8 \mathrm{~m}$ were maintained from the surface of the seawater and the seafloor, respectively.

\subsection{Observation of microstructure and corrosion morphology}

The welded joint, heat affected zone (HAZ), parent metal, and fusion line were retrieved along with other non-corroded welded specimens, processed and unprocessed by VSR, using techniques for the preparation of metallographic specimens. After retrieval, the surface size of the metallographic specimens was $30 \mathrm{~mm} \times 10 \mathrm{~mm}$, and the height of the specimens was $10 \mathrm{~mm}$. Surface treatment of metallographic specimens followed the GB/T13298-2015. After cleaning off specimen's surface, the surface was burnished by a mechanical grinding machine and polished by a polishing machine. Then, the metal surface was soaked in a mixed solution of $\mathrm{HNO}_{3}$ and alcohol to show the microstructure. $\mathrm{HNO}_{3}$ accounted for $5 \%$ of the eroded solution, and the eroding time was $45 \mathrm{~s}$. After making the metallographic specimens, the microstructures of various zones were observed with an optical microscope.

The corrosion products on the surface of corroded welded specimens were removed by $\mathrm{H}_{2} \mathrm{SO}_{4}$ solution, and a corrosion inhibitor of thiourea was added to the acid solution to protect the base material (GB 6384-86, UDC 669: 620. 193. 1). The surface morphologies of the welded joint, HAZ, parent metal, and fusion line were observed by scanning electron microscopy (SEM), and the corrosion characteristics of each zone were analyzed.

\section{Results}

\subsection{Residual stress measurements}

Figure 2 shows the transverse residual stress measurements of group A1. The transverse residual stress on the surface of the welded structure is tensile stress, and the peak stresses located in the weld centers are 155.83, 158.96, and 138.85 $\mathrm{MPa}$. The residual stress in the welded structures decreases with increasing distance from the weld center.

The transverse residual stress measurements of group A2 before and after VSR are shown in Figure 3. The residual stress of group A2 before VSR has the same distribution as that of group A1, while after VSR, the residual stress of group A2 is obviously reduced. The stress peaks of group A2 decrease from 186.56, 181.35, and 188.02 MPa to 53.87, 49.96,

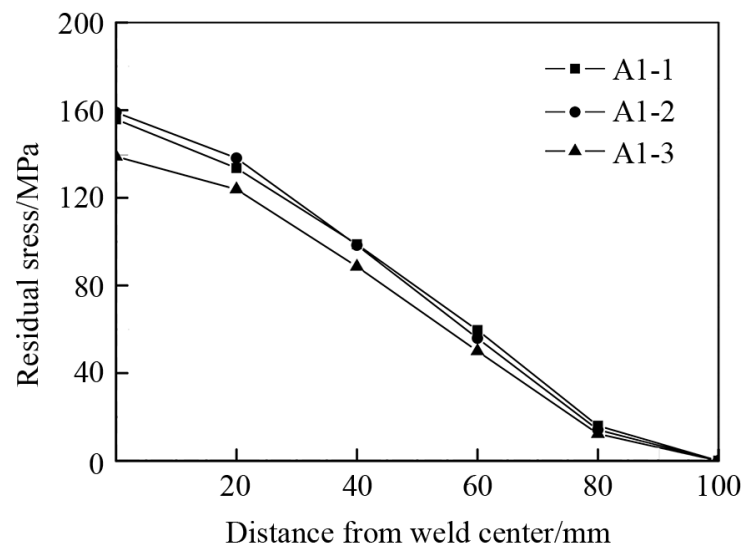

Figure 2. Transverse residual stress measurement of group A1

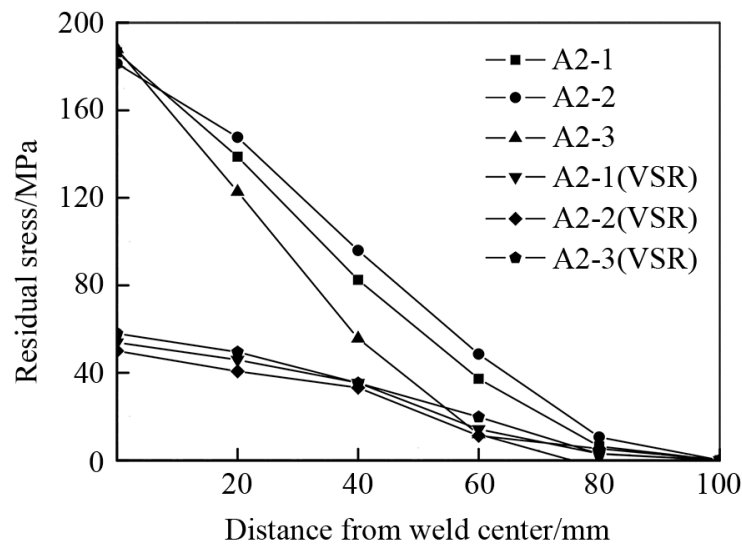

Figure 3. Transverse residual stress measurement of group A2

Table 3. Major chemical components of seawater from the East China Sea

\begin{tabular}{lcccccccc}
\hline Elements & $\mathrm{K}^{+}$ & $\mathrm{Na}^{+}$ & $\mathrm{Mg}^{2+}$ & $\mathrm{Ca}^{2+}$ & $\mathrm{HCO}_{3}^{-}$ & $\mathrm{Cl}^{-}$ & $\mathrm{SO}_{4}^{2-}$ & $\mathrm{SiO}_{2}$ \\
\hline $\mathrm{Mg} / \mathrm{L}$ & 354 & 9854 & 1182 & 385 & 130 & 17742 & 2477 & 0.9 \\
\hline
\end{tabular}


and 57.92 MPa, respectively, which represents the residual stress elimination effects of VSR, and meets expectations.

\subsection{Microstructure observation}

By comparing the microstructures among the welded joint, HAZ, parent metal, and fusion line of the welded structures processed and unprocessed by VSR, little difference was observed, which means that the VSR method has little influence on the microstructures of welded specimens. Microstructures of the welded joint, HAZ, parent metal, and fusion line are shown in Figure 4. During welding, the welded joint, whose microstructure is made of granular ferrite, acicular ferrite, and pearlite, is formed through crystal nucleation growth and solidification of the welding pool. Large amounts of granular pearlite distribute in the space between granular ferrite and acicular ferrite, making the microstructure of the welded joint finer (Figure 4 a). Crystal expansion and bulk ferrites of large size appear in HAZ due to the heat input while welding, and a small amount of bainite is deposited. Therefore, the microstructure of HAZ is mainly composed of granular ferrite, with a small amount of bainite (Figure $4 \mathrm{~b}$ ). The microstructure of parent metal suffers little heat input while welding and therefore has no significant change after welding. The microstructure of parent metal is mainly granular ferrite and pearlite (Figure $4 \mathrm{c}$ ). The volume of metal crystal between HAZ and the welded joint increases as more heat is absorbed, moreover, temperature gradient changes of the metal in the fusion line are greater while cooling, leading to the creation of Widmänstatten (Figure $4 \mathrm{~d}$ ).

\subsection{Corrosion morphology analysis}

A1-1 and A2-1 were selected for corrosion morphology analysis. The corrosion morphologies of the welded joints, HAZ, and parent metal are shown in Figure 5. The corrosion characteristic of both the specimens' welded joint is pitting corrosion. The damaged area and diameter of corrosion pits on the surface of the A1-1 welded joint is larger than those of A2-1, which means that the corrosion resistance of A1-1 is lower than that of A2-1. Although a few corrosion pits exist, the main corrosion characteristic of A1-1 HAZ resembles uniform corrosion, while that in A2-1 HAZ is pitting corrosion. Consecutive corrosion grooves are observed on the parent metal surface of A1-1 with a few etch pits, and the corrosion morphology on the bottom of grooves appear to be based on uniform corrosion (after 200 $\times$ magnification). The corrosion damage of the A2-1 parent metal, whose corrosion characteristic is based on pitting corrosion, is lower than that of A1-1 parent metal.

The corrosion morphologies near the fusion line of A1-1 and A2-1 are shown in Figure 6. Corrosion grooves were generated at the fusion line of both A1-1 and A2-1, however, the groove on the surface of A1-1 is deeper than that of A2-1. The welded joint near the fusion line of A1-1 shows serious pitting corrosion, with both the damage area and diameter of the etch pits much larger than that in any other areas of the welded joint. The degree of pitting of the A2-1 welded joint near the fusion line is more serious than at any other areas of A2-1 but less serious than that of A1-1. On the HAZ surface near the fusion line, the corrosion morphology of the A1-1 HAZ resembles uniform corrosion, and etch pits with large diameter are almost nonexistent. Although the corrosion morphology of the A2-1 HAZ surface near the fusion line resembles uniform corrosion, a small amount of etch pits with large diameter still exist.

\section{Mathematical Model}

\subsection{Energy Transformation Model}

To reveal the influence mechanism of the residual stress on the corrosion behavior of welded structures from the energy transformation perspective, the virtual work principle is required to introduce the residual stress into the energy transformation system. Metal unit $E$ close to the welded joint is studied as an object, whose force condition is shown in Figure 7.

According to elasticity mechanics, the virtual work equation is given by ${ }^{17}$ :

$$
\delta V_{\varepsilon}=\int_{V} \delta \nu_{\varepsilon} d \nu=\int_{V} f_{i} \delta u_{i} d \nu+\int_{S_{\sigma}} \bar{f}_{i} \delta u_{i} d s
$$

where $\delta V_{\varepsilon}$ : variation of elastomer strain energy; $f_{i}$ and $\bar{f}_{i}$ : body stress and surface stress of the elastomer in " $i$ " direction, respectively, and $\delta u_{i}$ : virtual displacement in " $i$ " direction $(i=x, y, z)$.

Since the residual stress is body stress, Equation (1) can also be represented as:

$$
\delta V_{\varepsilon}=\int_{V} \sum \sigma_{k} \delta u_{k}+\sum \tau_{i j} \delta u_{i j} d \nu
$$

where $\sigma_{k}$ : normal stress applied on the metal unit $E$, and $\tau_{i j:}$ shear stress applied on the metal unit $E(i, j, k=x, y, z)$.
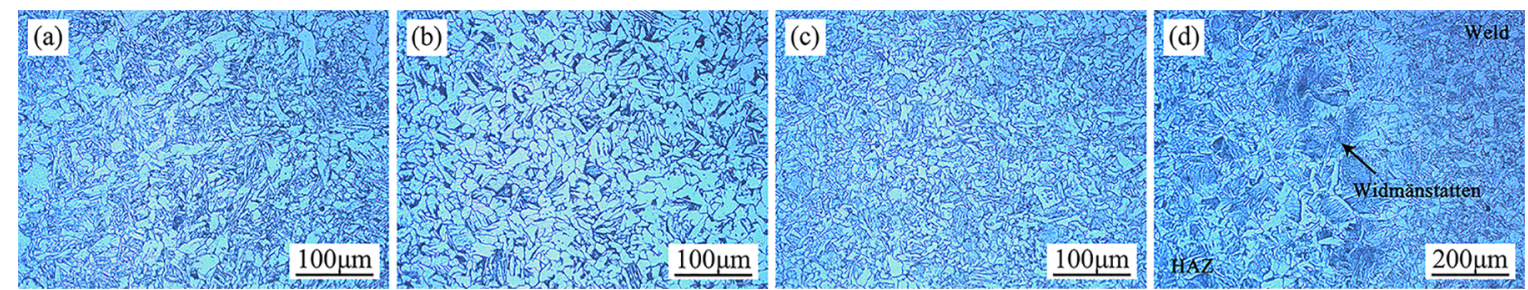

Figure 4. Microstructures of different areas of welded structure: (a) welded joint, (b) HAZ, (c) parent metal, and (d) fusion line 

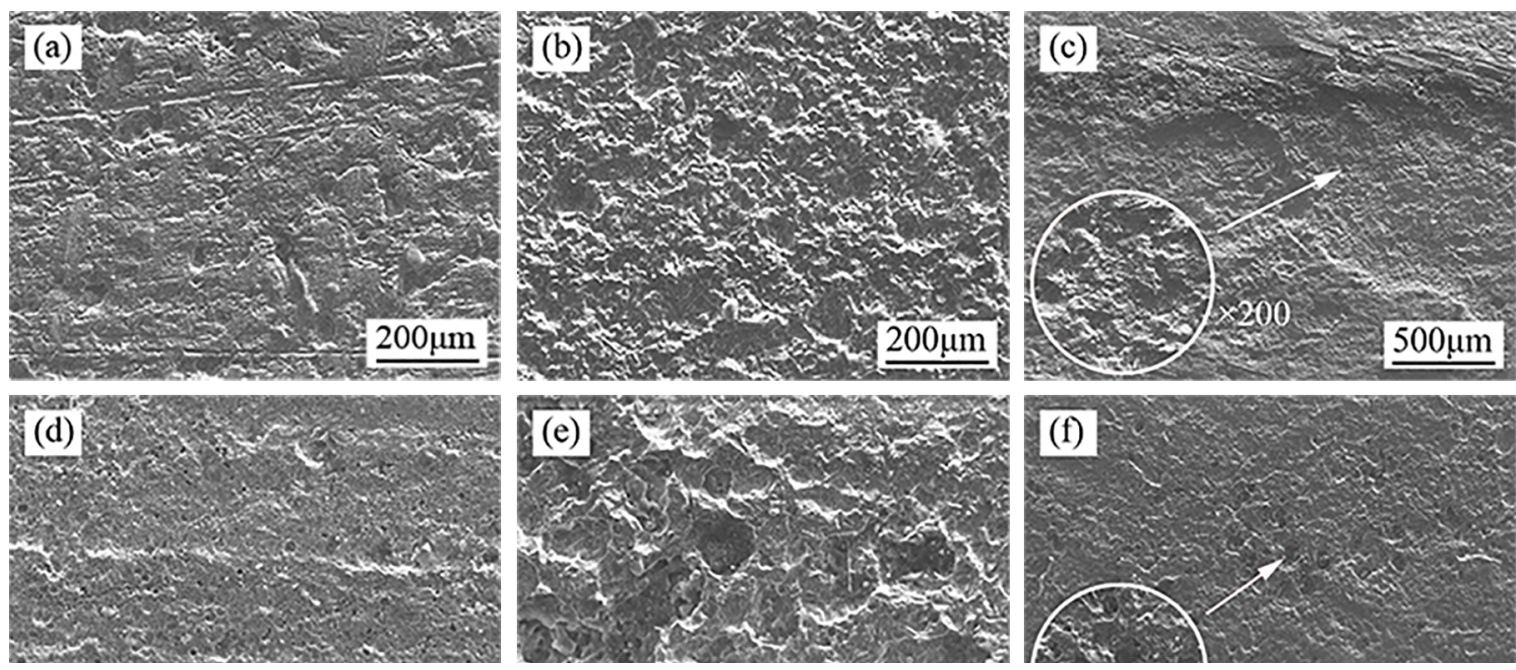

Figure 5. Surface corrosion morphologies of different areas of specimens: (a) welded joint of A1-1, (b) HAZ of A1-1, (c) parent metal of A1-1, (d) welded joint of A2-1, (e) HAZ of A2-1, and (f) parent metal of A2-1
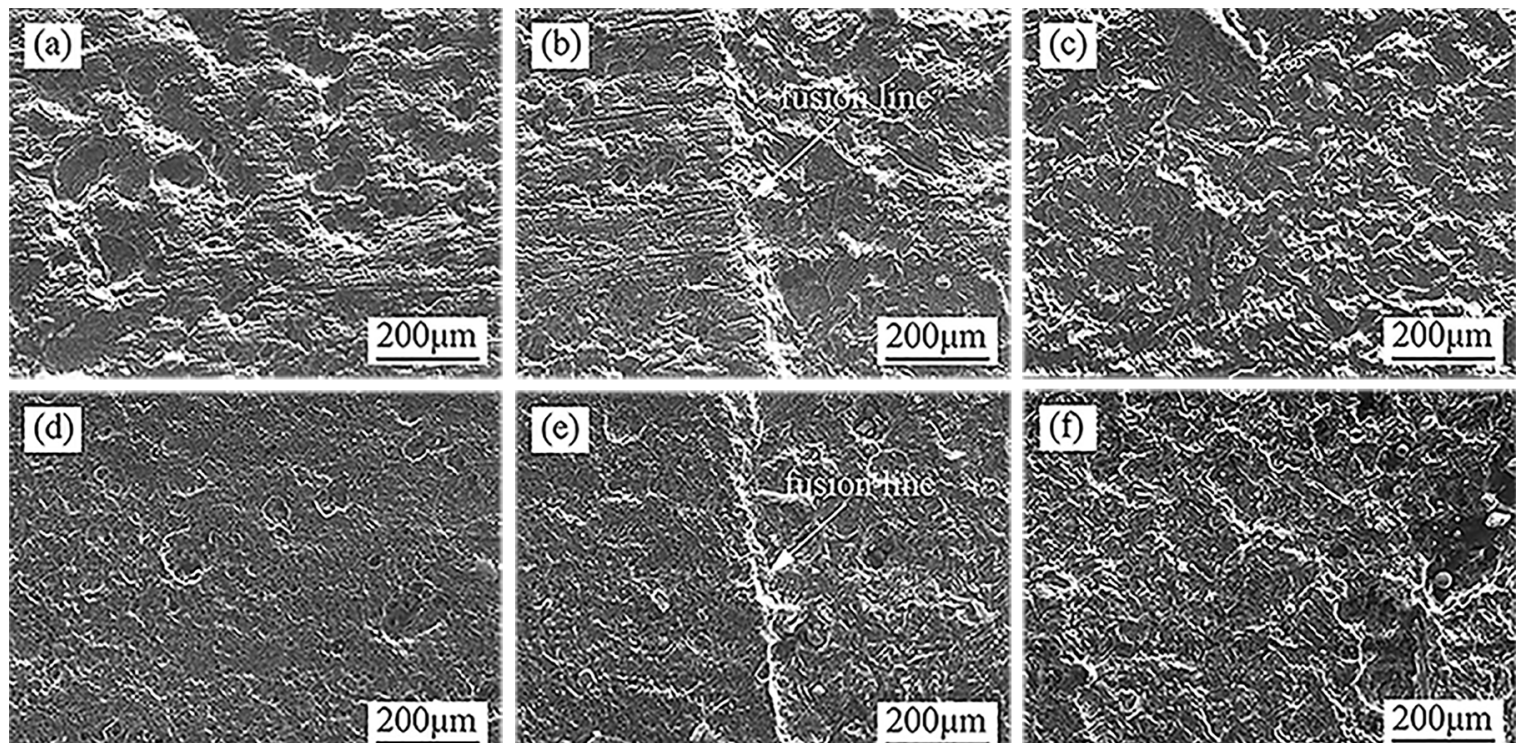

Figure 6. Surface corrosion morphologies near the fusion line: (a) welded joint surface of A1-1 near the fusion line, (b) fusion line of A1-1, (c) HAZ surface of A1-1 near the fusion line, (d) welded joint surface of A2-1 near the fusion line, (e) fusion line of A2-1, and (f) HAZ surface of A2-1 near the fusion line

Since virtual displacement has the same direction as that of the residual stress, irrespective of whether $E$ is applied by the residual tensile stress or compressive stress, the internal energy of $E$ increases.

The increase in internal energy manifests as a change of shape in the macroscopic view and a change in metal atom mobility in the microscopic view. It is assumed that the total electron number inside and outside the nucleus in $E$ and the temperature of $E$ are constant. Thus ${ }^{18}$,

$$
U_{i}=U_{o}
$$

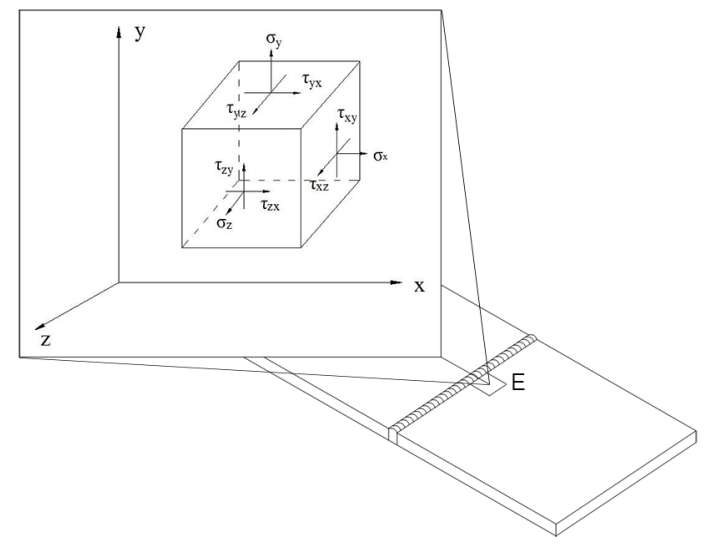

Figure 7. Force condition of metal unit E 
where $U_{i}$ : internal energy of $E$, and $U_{o}$ : sum of the energy of the electrons around the atoms inside $E$.

The arrangement of metal atom in the metallic crystal is determined by free electrons inside crystal lattice, and the bonding force of the free electrons is the essence of metallic bond $^{19}$. Therefore, the sum of the energy of the electrons is equal to the bond energy in metallic bond,

$$
U_{i}=U_{b}
$$

where $U_{b}$ : bond energy of metallic bond.

In the process of corrosion, metallic bonds between metal atoms break, resulting in the transformation of bond energy in the metallic bond to the electric energy and thermal energy. Additionally, the generation of electric energy and thermal energy increases as the bond energy increases.

Thus, the internal energy and the average electron energy level of $E$ increase under the influence of both residual tensile stress and residual compressive stress, and the average activation energy, needed by the metal atoms for converting into metal ions, decreases. Meanwhile, the residual stress raises the bond energy in the metallic bond, and then increases the corrosion current density generated in the process of corrosion. Therefore, the rate of the transformation from metal atoms to metal ions is increased. Ultimately, the corrosion rate of $E$ is accelerated by the residual stress.

\subsection{Corrosion-resistance constant model}

Electrochemical corrosion of metals is a conversion between metal atom $A$ and metal ion $B$ on the metal surface. While A transforms into B by passing over the electric double layer, A should be induced to become an activation molecule between the two electric layers. The electric field strength of the electric double layer in the phase boundary is uniform, with a value of

$$
\varepsilon=\frac{\Phi}{l}
$$

where $\Phi$ : potential difference of the electric double layer, and $l$ : distance of the electric double layer.

It is assumed that the surface atomic density of the metal electrode is $N$. When $N$ mol of A are activated by potential difference, the activation energy, $N \Delta G_{A \rightarrow B}^{*}$, is needed to counteract the effect of electric field. The variation value of enthalpy, $\Delta \bar{G}_{A \rightarrow B}^{*}$, can be calculated by:

$\Delta \bar{G}_{A \rightarrow B}^{*}=N \Delta G_{A \rightarrow B}^{*}-N n F \varepsilon \chi_{1}$, where $\Delta \bar{G}_{A \rightarrow B}^{*}>0$.

where $\Delta \bar{G}_{A \rightarrow B}^{*}$ : the activation energy needed by $1 \mathrm{~mol}$ of A to transform into $1 \mathrm{~mol}$ of $\mathrm{B} ; F$ : Faraday constant; $n$ : number of positive charges in $\mathrm{B}$, and $U_{i}$ : distance that $\mathrm{A}$ moves during transformation into activated molecule.
Similarly, the variation value of enthalpy when $N$ mol of $\mathrm{B}$ are activated can be calculated by:

$\Delta \bar{G}_{B \rightarrow A}^{*}=N \Delta G_{B \rightarrow A}^{*}+N n F \varepsilon \chi_{2}$, where $\Delta \bar{G}_{B \rightarrow A}^{*}>0$.

where $\chi_{2}$ : distance covered by B for transforming into activated molecule, and $\Delta \bar{G}_{B \rightarrow A}^{*}$ : activation energy needed by $1 \mathrm{~mol}$ of $\mathrm{B}$ to transform into $1 \mathrm{~mol}$ of $\mathrm{A}$,

According to the Arrhenius equation, the electrode reaction rate constants can be given as follows:

$$
\begin{aligned}
& \overleftarrow{k_{a}}=\frac{k T}{h} \exp \left(-\frac{\Delta \bar{G}_{B \rightarrow A}^{*}}{R T}\right) \\
& \overleftarrow{k_{a}}=\frac{k T}{h} \exp \left(-\frac{\Delta \bar{G}_{B \rightarrow A}^{*}}{R T}\right)
\end{aligned}
$$

where $\vec{k}_{a}$ : electrode reaction rate constant during the transformation from $\mathrm{A}$ to $\mathrm{B} ; \bar{k}_{a}$ : electrode reaction rate constant during the transformation from $\mathrm{B}$ to $\mathrm{A} ; k$ : Boltzmann

Table 4. Parameters used in the corrosion-resistance constant model

\begin{tabular}{lcccccc}
\hline $\boldsymbol{k} /\left(\mathrm{J} /{ }^{\circ} \mathrm{C}\right)$ & $\begin{array}{c}\boldsymbol{F} /(\mathrm{C} / \\
\mathrm{mol})\end{array}$ & $\boldsymbol{h} / \mathrm{J} \cdot \mathrm{s}$ & $\boldsymbol{x}_{1} / \boldsymbol{n}$ & $\boldsymbol{n}$ & $\boldsymbol{T} /{ }^{\circ} \mathrm{C}$ & $\Phi / \mathrm{V}$ \\
\hline $1.381 \times 10-23$ & 96485.33 & $6.26 \times 10-24$ & $1 / 2$ & 2 & 20 & 0.3 \\
\hline
\end{tabular}

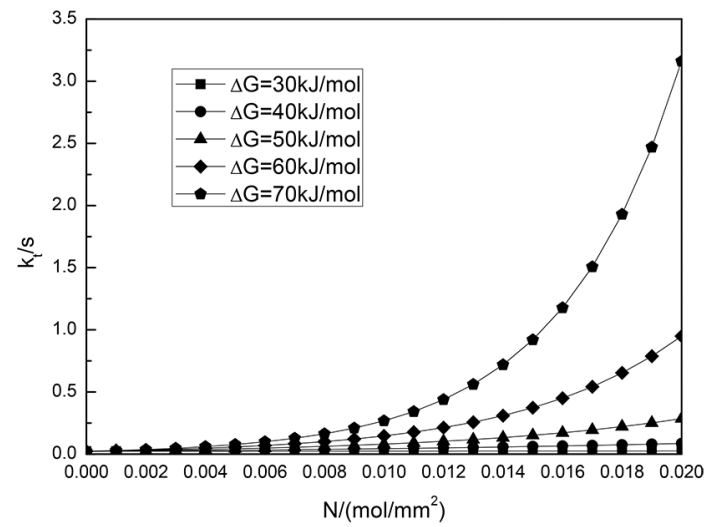

Figure 8. Relation curve between $\mathrm{N}$ and kt

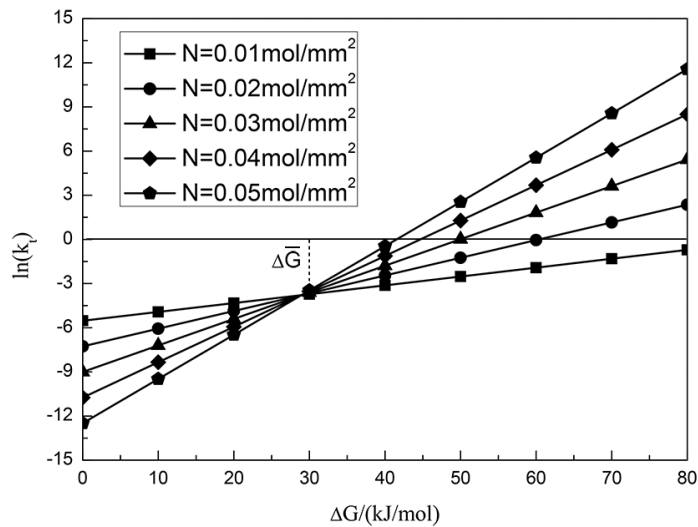

Figure 9. Relation curve between $\Delta \mathrm{G}$ and $\ln \left(\mathrm{k}_{\mathrm{t}}\right)$ 
constant; $R$ : molar gas constant; $h$ : Planck constant, and $T$ : temperature.

The electrode reaction rates can be represented as:

$$
\begin{aligned}
& \vec{v}=\vec{k}_{a} C_{A} \\
& \overleftarrow{v}=\overleftarrow{k}_{a} C_{B}
\end{aligned}
$$

where $\vec{\nu}$ : electrode reaction rate for the transformation from $\mathrm{A}$ to $\mathrm{B} ; \overleftarrow{\nu}$ : electrode reaction rate for the transformation from $\mathrm{B}$ to $\mathrm{A} ; C_{A}$ : atomic concentration of the metal electrode, which is equal to the surface atomic density $N$; and $C_{B}$ : metal ion concentration in the solution.

Since the metal ion concentration becomes quite low after diffusing into the corrosive medium during natural corrosion, we assume that $C_{B}=0$ and $C_{B}=N$. Thus, the overall reaction rate for the transformation from $\mathrm{A}$ to $\mathrm{B}$ is:

$$
\nu=\vec{\nu}-\overleftarrow{\nu}=\vec{k}_{a} N
$$

The time taken to corrode per unit area of metal can be modeled by the following function:

$$
k_{t}=\frac{N}{\nu}=\frac{1}{\vec{k}_{a}}
$$

To facilitate the analysis, $K_{t}$ is considered the corrosionresistance constant, which is used to measure the corrosion resistance of the metal. Equation (13) represents the corrosionresistance constant model, wherein the larger the value of $K_{t}$, the better is the corrosion resistance of the metal.

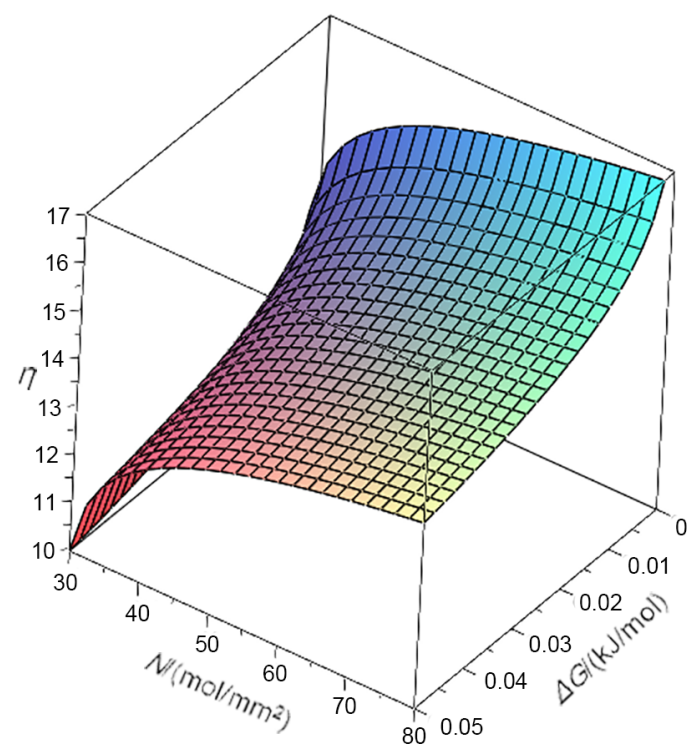

Figure 10. Variation of $\eta$ with $\Delta \mathrm{G}$ and $N$

\subsection{Example analysis}

The corrosion process, whose corrosion products are mainly $\mathrm{Fe}^{2+}$, is taken for illustration. The parameters of the corrosion-resistance constant model used in the example are summarized in Table 4. Curves of the corrosion-resistance constant versus surface atomic density show that the corrosion-resistance constant increases with increasing surface atomic density (Figure 8). The larger the activation energy, the greater is the change in the corrosion-resistance constant gradient with increasing surface atomic density.

The relationship between the activation energy $(\Delta G)$ and $\ln \left(k_{t}\right)$ shows that the increase in activation energy could increase the corrosion-resistance constant, increasing the corrosion resistance of the metal (Figure 9). The corrosionresistance constant increases with the decrease in surface atomic density when $\Delta G<\Delta \bar{G}$, but increases with the increase in surface atomic density when $\Delta G>\Delta \bar{G}$. Thus, the influence of the surface atomic density of metal on the corrosion-resistance constant is different because of the varying activation energy in different electrode reactions, and $\Delta \bar{G}$ needs to be recalculated according to the actual parameters in different electrode reactions.

It is assumed that the function $\eta$ is

$$
\eta=\ln \left(\frac{\partial k_{t}}{\partial N}\right)-\ln \left(\frac{\partial k_{t}}{\partial \Delta G}\right)
$$

where $\frac{\partial k_{t}}{\partial N}$ : change in the rate of corrosion-resistance constant with surface atomic density, and $\frac{\partial k_{t}}{\partial \Delta G}$ : change in the rate of corrosion-resistance constant with activation energy.

Irrespective of the change in activation energy and surface atomic density, the value of $\eta$ remains positive, implying that $\ln \left(\frac{\partial k_{t}}{N}\right)>\ln \left(\frac{\partial k_{t}}{\Delta G}\right)$ (Figure 10). Therefore, the surface atomic density has a greater influence on the corrosionresistance constant than does the activation energy. Notably, a lower surface atomic density and larger activation energy can enhance the influence of the surface atomic density on the corrosion-resistance constant.

\section{Analysis and Discussion}

\subsection{Analysis of corrosion morphology}

The experimental results show that the higher the residual tensile stress level on the surface of the welded structures, the lower the corrosion resistance of the metal will be. However, crystal structures in the welded joint could 
enter the austenite transition region when the temperature is higher than $700^{\circ} \mathrm{C}$ during welding, forming acicular ferrite and pearlite on cooling and increasing the corrosion resistance of the welded joint ${ }^{20}$. Thus, although a high-level residual tensile stress exists on the welded joint surface, the corrosion resistance of welded joint is still higher than that of the HAZ and parent metal.

Although the expansion in size of granular ferrite increases the corrosion resistance of HAZ, the bainite will separate away from the surface of HAZ while corroding, decreasing the corrosion resistance of HAZ to some extent. Meanwhile, the high-level residual tensile stress increases the internal energy of the structure and decreases the activation energy needed by the metal atoms to convert into metal ions, thereby decreasing the corrosion resistance of HAZ. The corrosion characteristic on the HAZ surface transforms from pitting corrosion to uniform corrosion since high-level residual tensile stress is dominant on the HAZ surface, and thus, the effect of galvanic corrosion is not obvious. The corrosion morphology of HAZ resembles that of pitting corrosion when the residual tensile stress level is low.

The average volume of granular ferrites on the surface of parent metal is smaller than that on the surface of welded joint, while there have more consecutive granular ferrites on the surface of parent metal. Thus, corrosion grooves are easier to generate on the surface of parent metal. Additionally, pearlite could enhance the local corrosion resistance of parent metal, inhibiting the consecutive growth of corrosion grooves. Meanwhile, the high-level residual tensile stress could promote the formation of the corrosion grooves on the surface of parent metal and the production of large-diameter pits outside the corrosion grooves, while the low-level residual tensile stress has little effect on the corrosion behavior of parent metal.

The depth of the corrosion groove at the fusion line increase with increasing residual tensile stress, indicating that the residual tensile stress is an important factor that renders the welded structure a high-damage area while corroding. The corrosion resistance of a welded joint near the fusion line decreases because of the reduction of pearlite, resulting in a more serious degree of pitting than any other areas of welded joint. Additionally, the pitting corrosion resistance of the welded joint that is close to fusion line is improved by Widmänstatten, leading to a lower pitting degree on the edge of the welded joint ${ }^{21}$.The residual tensile stress level on the HAZ surface near the fusion line is the highest on HAZ, which produces a large internal energy in the structure. Thus, the uniform corrosion characteristic on the surface of HAZ near the fusion line is more obvious, and the number of etch pits are fewer.

\subsection{Mechanism analysis of corrosion}

Activation energy needed for electrochemical corrosion is usually larger than $40 \mathrm{~kJ} / \mathrm{mol}$ in a natural environment ${ }^{22-24}$, which is higher than the $\Delta \bar{G}(28.95 \mathrm{~kJ} / \mathrm{mol})$ calculated by the mathematical model herein. The results of the corrosionresistance constant model indicate that the corrosion resistance of welded structures reduces with decreasing surface atomic density and activation energy (Figure 8,9), and the surface atomic density has a greater influence on the corrosion resistance of welded structures than does the activation energy (Figure 10). Meanwhile, the number of atoms per unit area on the metal surface decreases under the influence of residual tensile stress and increases under the influence of residual compressive stress. Specifically, the residual tensile stress and residual compressive stress could decrease and increase the surface atomic density of welded structures, respectively. Thus, the activation energy and surface atomic density can be decreased simultaneously by the residual tensile stress, decreasing the corrosion resistance of the welded structures. In contrast, the residual compressive stress can enhance the corrosion resistance of the welded structures by increasing the surface atomic density of welded structures, and the impact on corrosion resistance based on the reduction of activation energy is counteracted.

The experimental results show that the residual tensile stress can decrease the corrosion resistance, which is the same as that proposed by the theoretical results achieved from the energy transformation model and corrosion-resistance constant model. Therefore, the energy transformation model and corrosion-resistance constant model could be used to analyze the corrosion behavior of the welded structures, and then reveal the influence mechanism of residual stress on this corrosion behavior.

\section{Conclusion}

1. While low-level residual tensile stress has a stimulative effect on pitting corrosion, local galvanic corrosion is still the main influencing factor for the corrosion behavior of welded structures. Residual tensile stress will be the main factor affecting the corrosion behavior of the welded structures when the residual tensile stress becomes higher, and the corrosion characteristic of the surface is transformed from pitting corrosion to uniform corrosion.

2. Areas with the most serious corrosion damage occur near the fusion line because of the influences of high-level residual stress and the microstructure. The corrosion resistance near the fusion line is much lower than that further away from the fusion line, which renders the welded structure a high-damage area while corroding.

3. The energy transformation model and corrosionresistance constant model could explain the influence mechanism of residual stress on the corrosion 
behavior of welded structures, and could provide theoretical support for further research on corrosion.

4. Residual tensile stress can reduce activation energy and surface atomic density simultaneously, thereby decreasing the corrosion resistance of welded structures. However, residual compressive stress could increase the surface atomic density of the metal, thereby counteracting the impact on corrosion resistance based on the reduction of activation energy, and ultimately enhancing the corrosion resistance of welded structures.

\section{Acknowledgements}

This research work was financial supported by the Major State Basic Research Development of China (973 Program, Grant Nos. 2014CB046801).

\section{References}

1. Polezhayeva H, Toumpis AI, Galloway AM, Molter L, Ahmad B, Fitzpatrick ME. Fatigue performance of friction stir welded marine grade steel. International Journal of Fatigue. 2015;81:162170.

2. Wan HX, Du CW, Liu ZY, Song DD, Li XG. The effect of hydrogen on stress corrosion behavior of X65 steel welded joint in simulated deep sea environment. Ocean Engineering. 2016;114:216-223.

3. Ahmad B, Fitzpatrick ME. Analysis of Residual Stresses in Laser-Shock-Peened and Shot-Peened Marine Steel Welds. Metallurgical and Materials Transactions A. 2017;48(2):759770.

4. Wang Q, Liu X, Wang W, Yang C, Xiong X, Fang H. Mixed mode fatigue crack growth behavior of Ni-Cr-Mo-V high strength steel specimens. International Journal of Fatigue. 2017;102:79-91.

5. Raman RKS. Interplay of microbiological corrosion and alloy microstructure in stress corrosion cracking of weldments of advanced stainless steels. Sadhana. 2013;28(3-4):467-473.

6. Nakamura N, Ashida K, Takishita T, Ogi H, Hirao M. Inspection of stress corrosion cracking in welded stainless steel pipe using point-focusing electromagnetic-acoustic transducer. NDT \& E International. 2016;83:88-93.

7. Ma HC, Liu ZY, Du CW, Wang HR, Li XG, Zhang DW, et al. Stress corrosion cracking of E690 steel as a welded joint in a simulated marine atmosphere containing sulphur dioxide. Corrosion Science. 2015;100:627-641.

8. Poklyatskii AG, Fedorchuk VE, Yavorskaya MR. StressCorrosion Cracking Resistance of AMG-5M Alloy Obtained by Nonconsumable-Electrode Argon-Arc Welding and Friction stir Welding. Materials Science. 2016;51(5):682-690.

9. Sridhar BR, Devananda G, Ramachandra K, Bhat R. Effect of machining parameters and heat treatment on the residual stress distribution in titanium alloy IMI-834. Journal of Materials Processing Technology. 2003;139(1-3):628-634.
10. Sun MC, Sun YH, Wang RK. Vibratory stress relieving of welded sheet steels of low alloy high strength steel. Materials Letters. 2004;58(7-8):1396-1399.

11. Zhu ZQ, Chen LG, Rao DL. Relieving Welding Residual Stress by Applying Vibratory Weld Conditioning. Materials Science Forum. 2005;490-491:475-480.

12. Kumar MV, Balasubramanian V, Rajakumar S, Albert SK. Stress corrosion cracking behaviour of gas tungsten arc welded super austenitic stainless steel joints. Defence Technology. 2015;11(3):282-291.

13. Nazir MH, Khan ZA, Saeed A, Stokes K. Modelling the Effect of Residual and Diffusion-Induced Stresses on corrosion at the Interface of Coating and Substrate. Corrosion. 2016;72(4):500517.

14. Ming HL, Zhu RL, Zhang ZM, Wang JQ, Han EH, Ke W, et al. Microstructure, local mechanical properties and stress corrosion cracking susceptibility of an SA508-52M-316LN safe-end dissimilar metal weld joint by GTAW. Materials Science \& Engineering: A. 2016;669:279-290.

15. Savguira $Y$, North TH, Thorpe SJ. Effect of grain size and residual stress on the corrosion resistance of friction stir spot welded AZ31B joints. Materials and Corrosion. 2016;67(10):10681074.

16. Jeuken LJC, McEvoy JP, Armstrong FA. Insights into Gated Electron-Transfer Kinetics at the Electrode-Protein Interface: A Square Wave Voltammetry Study of the Blue Copper Protein Azurin. Journal of Physical Chemistry B. 2002;106(9):23042313.

17. Chen GR. Mechanics Elasticity. 2nd ed. Nanjing: Hehai University Press; 2005.

18. Zhou GD. Basis of Chemical Structure. 3rd ed. Beijing: Peking University Press; 1995.

19. Gu GB. Inorganic Chemistry. 4th ed. Beijing: Chemical Industry Press; 2015.

20. Ren SZ. Principle and technology of metallography analysis. $1^{\text {st }}$ ed. Shanghai: Shanghai Science and Technology Literature Press; 2012. Available from: <http://www.bookdao.com/ book/1979151/>. Access in: 28/02/2018.

21. Rodrigues CAD, Pagotto JF, Motheo AJ, Tremiliosi-Filho G. The effect of titanium on pitting corrosion resistance of welded supermartensitic stainless steel. Corrosion Engineering, Science and Technology. 2017;52(2):141-148.

22. Huang YH, Qin CL, Qin D. The research of corrosive behavior of low carbon disreinforcing steel bar in $\mathrm{HCl}$ medium. Journal of Hechi Normal College (Natural Sciences). 2002;22(4):5355. Available from: $<$ http://210.44.192.141/20884/KCMS/ detail/detail.asp ? dbcode $=$ CJFQ $\&$ dbname $=$ CJFD2002 \&fil ename $=$ HCSF200204015\&uid=WEEvREcwSIJHSIdRa1Fh b09jSnZqckVYQ1JnQWlkV004eHBvdTJjQjg4az0=\$9A4 hF_YAuvQ5obgVAqNKPCYcEjKensW4ggI8Fm4gTkoUKaID $\bar{j}$ j8gFw!!\&v=MDU2NTZZWVI4ZVgxTHV4WVM3RGg xVDNxVHJXTTFGckNVUkxLZ11PZHZGQ3ZtVUwvTUx TN1lhTEc0SHRQTXE0OUU>. Access in: 28/02/2018. 
23. Zhao JG. Electrochemical corrosion behavior of Q235 steel in OPP-Brine system. Corrosion \& Protection. 2008;29(8):454456.
24. Lu ZP, Chen JJ. Effects of temperature on stress corrosion cracking of austenitic stainless steels in high temperature water. Corrosion \& Protection. 2015;36(9):803-809. 